\title{
Cláusulas absolutas y construcciones afines en español: la correferencia y la presencia/ausencia del sujeto como rasgos distintivos
}

\author{
Girex Eloundou Eloundou \\ Universidad de Ngaoundéré \\ girexeloundou@yahoo.fr \\ https://dx.doi.org.10.12795/futhark.2020.il5.05
}

Fecha de recepción: 28.03 .2020

Fecha de aceptación: 10.04.2020

Resumen: Las cuestiones de la correferencia del SN-sujeto con un elemento de la oración principal y la de su presencia o ausencia son unas de las más debatidas en las gramáticas en cuanto al tema de las cláusulas absolutas se refiere. El objetivo perseguido en este trabajo es demostrar que estos rasgos sintácticos (correferencia y presencia/ausencia) del sujeto permiten distinguir las cláusulas absolutas de estructuras afines tales como las construcciones concertadas, los adjetivos incidentales, las cláusulas semiabsolutas y las pseudoabsolutas. En el análisis, nos fundamentamos en una perspectiva descriptiva con una terminología tradicional, y recurrimos a veces a las estructuras latinas correspondientes para poner de relieve las diferencias formales $y$ estructurales inducidas por la correferencia y la presencia/ausencia del sujeto en estas construcciones.

Palabras clave: correferencia, elipsis, SN-sujeto, cláusulas absolutas, construcciones concertadas.

\section{Absolute clauses and related constructions in Spanish: the conferences and the presence/absence of the subject as distinctive features}

\begin{abstract}
The questions of the coreference of the NP-subject with an element of the main sentence and that of its presence or absence are some of the most debated in grammars as far as the absolute clauses are concerned. The objective pursued in this work is to demonstrate that these syntactic features (coreference and presence / absence) of the subject make it possible to distinguish absolute
\end{abstract}


clauses from related structures such as concerted constructions, incidental adjectives, semiabsolute and pseudo-absolute clauses. In the analysis, we base ourselves on a descriptive perspective with a traditional terminology, and sometimes we resort to the corresponding Latin structures to highlight the formal and structural differences induced by the coreference and the presence / absence of the subject in these constructions.

Keywords: coreference, ellipsis, NP-subject, absolute clauses, concerted constructions

Sumario: Introducción. I. La correferencia del sujeto: las construcciones concertadas y las cláusulas absolutas. 2. Las cláusulas pseudoabsolutas y las semiabsolutas. 3. La presencia/ausencia del sujeto: los adjetivos incidentales y las cláusulas absolutas. Conclusión.

\section{Introducción}

Según define la RAE (2009: §38.6), las cláusulas absolutas “son unidades bimembres de predicación que establecen una relación atributiva entre un elemento nominal (raramente oracional) y algún atributo que se predica de él sin que medie entre ellos un verbo". Uno de los puntos sobre los que se detienen la mayoría de los autores que estudian estas construcciones es la correferencia de su $\mathrm{SN}$-sujeto con algún elemento de la oración principal con la que se relacionan dichas construcciones. Aunque señalaba Bello (1847: §II73) que las cláusulas absolutas "no tienen conexión gramatical con el resto de la sentencia", muchos autores consideran que el SN-sujeto de estas construcciones puede tener alguna relación con un elemento de la oración principal. Para Hernanz (1991: 81), De Miguel (1992: 64) o Hernanz y Suñer (1999), su SN-sujeto puede ser correferente o no con un SN de la oración principal. Fernández Leborans (1995: 366) advierte que en una cláusula absoluta el sujeto, expreso o tácito, puede ser correferente o no con un SN de la oración principal. Marín (2000: 221-254) llega a distinguir, según las características sintácticas y semánticas que poseen estas estructuras, dos tipos de cláusulas absolutas: las aspectuales y las predicativas. Según él, las aspectuales son aquellas que tienen un $\mathrm{SN}$-sujeto que no corresponde, en general, con ningún SN de la oración principal. En las predicativas, el SN-sujeto es vacío y, por lo general, correferente con un SN de la oración principal. Como se puede constatar, la cuestión de la correferencia del $\mathrm{SN}$-sujeto en estas construcciones está estrechamente relacionada con la de su presencia/ausencia. Este es uno de los puntos, por no decir el punto, de mayor discordancia entre los autores. Para unos, como Hernanz (1991), De Miguel (1992), Gómez Torrego (2000) o Suñer (2013), las construcciones con SN tácito no forman parte del paradigma de las cláusulas absolutas, aunque para otros, como Fernández Leborans (1995), Martínez (1994), 
Gutiérrez Ordóñez (1997) o Pérez Jiménez (2006), la presencia del SN es opcional. Con respecto a esta última postura, ya señalaba Bello (1847: §I 175) que "callase a veces el sustantivo por hallarse a poca distancia". En general, los autores que abogan por las cláusulas absolutas con sujetos tácitos se apoyan en su correferencia con un elemento de la oración principal como una condición sine qua non de la gramaticalidad de dichas estructuras. Por ejemplo, López (1994: 45) observa que, cuando el SN-sujeto no es fonéticamente realizado en la cláusula absoluta, debe ser controlado por uno de los constituyentes de la oración principal:

(I) a. Sitiada durante varios meses, la ciudad tuvo que rendirse.

b. Declarada en estado de emergencia por tercera vez en pocos meses, el gobierno decidió enviar refuerzos militares a [la ciudad de Ayacucho].

También se admiten los sujetos explícitos correferentes con un elemento de la oración principal (Hernanz y Suñer 1999; Martínez 1994):

(2) a. Restaurada la estatua, volvió a ser ubicada en su emplazamiento original.

b. Cortadas las verduras en juliana, se fríen en la sartén.

En este trabajo, asumiremos la concepción tradicional según la cual estas construcciones no deben tener ninguna relación sintáctica con la oración principal y su sujeto puede ser tácito o expreso. Para sustentar esta postura, volveremos sobre algunas construcciones afines a las cláusulas absolutas cuyos rasgos definitorios tienen incidencia sobre las cuestiones que abordamos en este trabajo: la correferencia y la presencia/ausencia del sujeto de las construcciones absolutas. Con respecto a esos rasgos sintácticos, pondremos en paralelo las cláusulas absolutas con construcciones tales como las construcciones concertadas, los adjetivos incidentales y las cláusulas semi- y pseudoabsolutas. En este análisis, nos fundamentaremos en una perspectiva esencialmente descriptiva, adoptando una terminología tradicional.

\section{La correferencia del sujeto: las construcciones concertadas y las cláusulas absolutas}

Las construcciones concertadas son tan antiguas como las cláusulas absolutas aunque no hayan recibido mucha atención como estas en las gramáticas. Sus orígenes también se remontan a la sintaxis latina. Las dos construcciones proceden de estructuras con participios que ya tenían muchas similitudes en latín: 
los ablativos absolutos y los participios concertados. Si las definiciones de los ablativos absolutos abundan en la bibliografía consultada, son muy escasas aquellas referentes a las construcciones concertadas. Entre las múltiples caracterizaciones de los ablativos absolutos encontradas, la definición de Touratier (1994: 655) es una de las más concisas: "On appelle ablatif absolu une proposition subordonnée participiale dont le sujet et le verbe au participe se mettent tous deux à l'ablatif". Si se considera generalmente que en la construcción concertada el sujeto del verbo (participio) concuerda en género, número y en caso con un sustantivo (cualquiera) de la oración principal, en Vangaever (2018: 27-28), y en las referencias que allí se citan, se restringe dicha correspondencia con el $\mathrm{SN}$-sujeto del predicado de la oración regente'; postura que también compartimos.

De hecho, las dos construcciones son estructuras bimembres formadas por un participio y otro elemento de carácter nominal, con valor de subordinada adverbial (y también adjetiva para el participio concertado). Una de las diferencias sustanciales entre ambas construcciones ${ }^{2}$, en sus caracterizaciones estándares, y que aquí nos interesa, radica en las relaciones sintácticas que mantienen con la oración principal con la que concurren. Los ablativos absolutos son, en su forma estándar, construcciones desligadas; es decir, no guardan ninguna relación sintáctica con la oración regente, mientras que los participios concertados se relacionan con el sujeto de la oración principal. Recordamos a este respeto que se ha aludido, repetidas veces, a la falta de conexión sintáctica con la oración principal como uno de los rasgos formales de los ablativos absolutos. Para Ernout y Thomas (1972: $\S$ 127): "L'ablatif absolu étant une détermination autonome, les écrivains évitent de recourir à l'ablatif absolu quand il est possible d'en faire accorder les termes avec un autre mot de la phrase; sujet, accusatif d'objet, régime indirect au datif". Serbat (1979: 34I) considera que "L'ablatif absolu ne doit pas s'employer lorsque son sujet est repris par un terme quelconque de la proposition régissante. C'est en raison du caractère "absolu" (= "détaché"), "autonome", (...) que son sujet ne peut être repris dans la principale". Hoff (1989: 402) apunta que "les deux constituants nucléaires de l'ablatif absolu doivent être extérieurs à la phrase à laquelle il s'adjoint: la règle usuelle interdit toute coréférence entre un constituant de l'ablatif absolu et un autre constituant de la phrase". Touratier (1994: 656) precisa a modo de norma: "On enseigne généralement que le sujet de l'ablatif absolu ne doit pas être répété, ni même repris par un anaphorique, en dehors de la subordonnée participiale". Incluso Ramat (1994: 262) subraya en inglés: "The NP forming

\footnotetext{
I La exclusividad reservada al SN-sujeto no parece ser algo fortuito. También en las subordinadas de infinitivo, por ejemplo, el sujeto expreso no debe repetirse en la proposición cuando es idéntico al de la oración principal (quiero que tu vengas, *quiero que yo venga, quiero venir).

${ }^{2}$ Vid. Tarriño Ruiz (2000: 30 y sigs.) para una revisión de la literatura sobre los rasgos distintivos de estas construcciones.

Futhark I5 (2020) 
Ablative Absolute has no syntactic relation with other elements of the finite sentence“.

Sin embargo, cabe mencionar que se ha acudido a casos en los que los ablativos absolutos tenían relación (correferencia) sintáctica con la oración principal para matizar este principio (Bizos 1965: 62; Rubio 1966: 161). Por otra parte, se indica en Hoff (1989) y Gayno (2015), entre otros, que estos son casos anormales provocados por condiciones especiales. Desde nuestra perspectiva, consideramos que, como veremos más tarde con las construcciones españolas, gran parte de estas construcciones han de ser consideradas como concertadas (de acuerdo con la caracterización de Vangaever [2018]) y otras como pseudoabsolutas. De momento, nos ocuparemos de las construcciones cuyos sujetos son correferentes con aquellos de la oración matriz. Volveremos sobre el caso de la correferencia con los complementos verbales más tarde.

Pensamos que la distinción absoluta/concertada mantenida en latín a propósito de estas construcciones también debe seguir vigente para el español. En efecto, las construcciones cuyo sujeto es correferente con el SN-sujeto de la oración principal parecen tener, a veces, un comportamiento sintáctico distinto de las construcciones absolutas, en cuanto a su ubicación con respecto a la oración regente. En muchos trabajos, se alude a la libertad posicional de las construcciones absolutas como uno de sus rasgos característicos, precisando que pueden aparecer antes, después o en el interior de la oración matriz (terminada la fiesta, los invitados regresaron; los invitados regresaron terminada la fiesta; los invitados, terminada la fiesta, regresaron). Sin embargo, esta característica no parece cumplirse de la misma forma en las construcciones cuyo sujeto es correferente con el de la oración principal, puesto que algunas posiciones pueden llevar modificaciones en el sentido global de la enunciación o acarrear ambigüedad:

(3) a. Cansado el padre, interrumpió el trabajo.

b. Interrumpió el trabajo cansado el padre.

c. (él/*el padre), cansado el padre, interrumpió el trabajo.

(4) a. Cansado el padre, sus trabajos se interrumpieron.

b. Sus trabajos se interrumpieron, cansado el padre.

c. Sus trabajos, cansado el padre, se interrumpieron.

Cuando el sujeto de la cláusula es idéntico (3a) o correferente (4a) con el de la oración matriz, la posición interna y la posposición de la cláusula pueden cambiar el sentido del enunciado en cuanto a la interpretación de los sujetos. La coincidencia entre los dos sujetos se tambalea hasta tal punto que se puede considerar que ya no designan la misma entidad, sino que reenvían a dos seres 
distintos: 'alguien interrumpió el trabajo porque (o cuando) el padre se cansó', 'los trabajos de alguien se interrumpieron porque (o cuando) el padre se cansó'. Así, el cambio de posición de la cláusula quebranta, más o menos, la coincidencia de los dos sujetos y puede provocar confusión en la interpretación.

Los casos de cláusulas absolutas cuyo sujeto es un pronombre personal pueden constituir una excepción a lo que acabamos de observar. En efecto, en estos casos, los cambios de posición de la cláusula no generan una interpretación obvia en cuanto a la referencia de los sujetos:

(5) a. Cansado él, sus trabajos se interrumpieron.

b. Sus trabajos se interrumpieron, cansado él.

c. Sus trabajos, cansado él, se interrumpieron.

(6) a. Ausentes nosotros, nuestros sitios fueron ocupados por otros.

b. Nuestros sitios fueron ocupados por otros, ausentes nosotros.

c. Nuestros sitios, ausentes nosotros, fueron ocupados por otros.

A diferencia de los ejemplos de (3 y 4), la relación de coincidencia entre el pronombre personal y el sustantivo referente es más vigente en $(5$ y 6$)$. Esta discrepancia entre los sustantivos y los pronombres se explica por el hecho de que los pronombres en general son (con ciertos adverbios) elementos anafóricos por excelencia. Como indica la RAE (2009: 299), los pronombres personales se caracterizan por designar a los participantes en el discurso. Entonces, las posiciones interna y final de la cláusula absoluta no alteran la referencia entre su pronombre personal sujeto y el sustantivo sujeto de la oración principal. Más bien, estas posiciones refuerzan su rasgo [+anafórico] posibilitando un contexto en que dichos pronombres se encuentren después de los sustantivos (antecedentes) con los cuales coinciden.

\section{Las cláusulas pseudoabsolutas y las semiabsolutas}

Hallamos la expresión 'cláusulas pseudoabsolutas' en De Roberto (2012). Analizando los ablativos absolutos latinos, esta autora observa que las más prototípicas de estas construcciones, en cuanto a su estructura se refiere, son las que tienen un sujeto no correferente con el de la oración regente. Ella acude a esta expresión para referirse a los dos casos que hemos tratado anteriormente, esto es, las cláusulas con $\mathrm{SN}$-sujeto correferente con el del predicado regente y aquellas con sujetos tácitos. En efecto, De Roberto (2012: 287 y sigs.) considera que las construcciones que no tienen un sujeto expreso o que lo tienen con la particularidad de que es correferente con el de la oración principal son

\begin{tabular}{lll}
\hline Futhark I5 (2020) & $\mathbf{6 8}$
\end{tabular}


pseudoabsolutas. Como vimos anteriormente, estas construcciones son, en realidad, construcciones concertadas y adjetivos. Sin embargo, es necesario que volvamos sobre un caso que pusimos de lado al inicio y que también los 'pseudoabsolutos' de De Roberto (2012) no toman en cuenta; esto es, la posibilidad de que el sujeto coincida con un SN del predicado principal que no sea al sujeto. A diferencia de las construcciones concertadas vistas anteriormente, su posición interna y final no conlleva matices semánticos en cuanto a la diferenciación de los sujetos:

(7) a. Viejo el padre, los niños ya no se acordaron de su cara.

b. Los niños, viejo el padre, ya no se acordaron de su cara.

c. Los niños ya no se acordaron de su cara, viejo el padre.

(8) a. Atrapados los bandidos, el guardia los metió en la cárcel.

b. El guardia, atrapados los bandidos, los metió en la cárcel.

c. El guardia los metió en la cárcel, atrapados los bandidos.

(9) a. Llegado el profesor, los nuevos alumnos le entregaron sus cartas.

b. Los nuevos alumnos, llegado el profesor, le entregaron sus cartas.

c. Los nuevos alumnos le entregaron sus cartas, llegado el profesor.

En estos ejemplos, el sujeto de la cláusula es correferente con el complemento de régimen (7a), el objeto directo (8a) y el indirecto (9a). Se puede observar en (5b; 6 b y $7 b$ ) que, como en las construcciones absolutas canónicas, el sujeto de estas construcciones (en posiciones mediales) no presenta ninguna confusión en lo que se refiere a su identificación y demarcación con respecto al sujeto del verbo de la oración matriz. Frente a esta evidencia, usaremos el término 'semiabsolutas' para referirnos a aquellas cuyo sujeto es correferente con un SN complemento del verbo de la oración principal.

Sin embargo, cabe mencionar que este término ya ha sido usado en bibliografía para evocar realidades distintas. Por ejemplo, Meilán García (1991: 28829I) considera que las construcciones semiabsolutas son aquellas en que falta el sujeto del participio o del gerundio, quedando de este modo solo la forma no personal del verbo en función incidental. Martínez (I994: 5.4.) usa la expresión 'semi-absolutas' para referirse a las construcciones absolutas formadas con 
infinitivos como la que aparece en Al salir el padre, los niños se pusieron nerviosos. Este autor observa que las construcciones con infinitivos expresan valores circunstanciales idénticos como los expresados por las construcciones de participio o de gerundio. Recurre al término 'semi' porque a las construcciones con infinitivo, a diferencia de las formadas por el participio o el gerundio, las precede una preposición. En efecto, una de las características señaladas repetidas veces en las descripciones de las construcciones absolutas es la falta de un nexo que indique el tipo de relación semántica conceptual que mantienen dichas construcciones con la oración principal. En una concepción totalmente diferente, Lorian (1973: 209) emplea el término 'semi-absolu' para referirse a construcciones absolutas en francés que se desarrollan en torno a verbos intransitivos, concretamente inacusativos, del tipo 'la nuit venue, tous s'endormirent'.

Frente a todas estas discrepancias, cabe volver en principio sobre la etimología del término 'absoluto' para adoptar un postulado. Este término deriva del latín absolutum, que significa "aflojar de" o "separados". A partir de eso, se debe entender que las cláusulas absolutas no están unidas sintácticamente a la oración principal. A este respecto, no nos alejamos tanto de De Roberto (2012: 24), que explica que el adjetivo absoluto induce la falta de correfencialidad entre el sujeto de la cláusula y el del predicado regente. Como vimos, cuando los dos coinciden, estamos ante una construcción concertada. De ahí, pensamos que es juicioso reservar el calificativo de semiabsolutas a aquellas cuyo sujeto es correferente con un $\mathrm{SN}$ complemento del predicado de la oración matriz.

En cuanto a las construcciones de infinitivo a las que alude Martínez (1994), hemos de observar que puede ocurrir que no presenten ningún lazo sintáctico con la oración principal (Al entrar el profesor, los alumnos se levantaron). Según lo que venimos defendiendo, también pueden ser concertadas (sujeto correferente con el del predicado principal) o semiabsolutas (sujeto correferente con un SN complemento del predicado regente). El único requisito que siempre incumplen es el hecho de ir precedidas por uno nexo (que indica, más o menos, el tipo de relación semántica que mantienen con la oración principal). Por lo tanto, las denominaremos 'cláusulas pseudoabsolutas'.

\section{La presencia/ausencia del sujeto: los adjetivos incidentales y las cláusulas absolutas}

La elipsis consiste en omitir en el enunciado una o más palabras sin que la oración resultante sea agramatical. La cuestión de la presencia/ausencia del SNsujeto de las cláusulas absolutas está estrechamente relacionada con su correferencia con el del predicado de la oración matriz. Muchos autores postulan que, cuando el sujeto de la construcción absoluta es tácito, debe ser correferente 
con el de la oración principal (Marín, 2000). Por otra parte, sabido es que en español puede aparecer un adjetivo en la posición del participio en la cláusula absoluta. Así, en un enunciado del tipo 'cansado, el padre interrumpió el trabajo', el adjetivo incidental 'cansado' sería una cláusula absoluta (con sujeto tácito). Sin embargo, esta construcción no es en realidad tan distinta de las que acabamos de estudiar (ejemplos de 3). Si se considera que el adjetivo 'cansado' en este ejemplo forma una construcción con un elemento tácito, su análisis como tal exige, en principio, que se recupere este elemento. Esta tarea, si nos dedicáramos a ella, nos llevaría a la situación anteriormente descrita; es decir, una construcción cuyo SNsujeto coincide con el del predicado principal: 'cansado (él/*el padre), el padre interrumpió el trabajo'.

Además, como ya indicó Lapesa (1975: 190), los adjetivos incidentales se distinguen de las cláusulas absolutas por el hecho de que se refieren a algún SN de la oración matriz.

No obstante, hace faltar notar que podemos tener casos en los cuales el sujeto tácito del adjetivo o participio no es correferente con algún $\mathrm{SN}$ de la oración regente, sino con un elemento del decurso anterior:

(10) a. La fiesta fue muy animada; terminada, los invitados se quedaron en casa de los novios.

b. Había mucho ruido en el congreso; tan animado, el diputado interrumpió su discurso.

Al recuperar, por catálisis, los sujetos de los adjetivos 'terminada' en ( $10 \mathrm{a})$ y 'animado' en ( $\mathrm{lOb})$, vemos que las construcciones resultantes son verdaderas cláusulas absolutas:

(II) a. La fiesta fue muy animada; terminada esta, los invitados se quedaron en casa de los novios.

b. Había mucho ruido en el congreso; tan animado eso, el diputado interrumpió su discurso.

\section{Conclusión}

En este análisis hemos procurado distinguir cláusulas absolutas de construcciones afines a partir de dos rasgos esenciales para dichas estructuras que son la correferencia y la presencia/ausencia del sujeto. De acuerdo con la correferencia, hemos distinguido las cláusulas absolutas de las construcciones 
concertadas, inspirándonos así en la distinción mantenida ya en latín. Además, hemos observado que las construcciones concertadas, por tener un sujeto correferente con el de la oración principal, se distinguen de las cláusulas absolutas en cuanto a su colocación en la oración. A medio camino entre estos dos tipos de construcciones están las semiabsolutas, construcciones cuyo sujeto es correferente con algún SN complemento del verbo de la oración principal. Sus posiciones internas y anteriores a la oración principal no generan disyunción en cuanto a la referencia de su sujeto y el de dicha oración. En cuanto al segundo rasgo, vimos que las construcciones cuyos sujetos tácitos son correferentes con los de la oración principal no son tan diferentes de las construcciones concertadas desde el punto de vista formal. Sin embargo, aquellas cuyos sujetos tácitos son recuperables a partir de un elemento anterior no integrante de la oración regente pueden ser consideradas como absolutas.

\section{Referencias bibliográficas}

BELLO, A. (1847). Gramática de la lengua castellana. Madrid: Edaf. Edición electrónica: http://www.cervantesvirtual.com.

BIZOS, M. (1965). Syntaxe latine. Paris: Librairie Vuibert.

DE MIGUEL, E. (1992). El aspecto en la sintaxis del español: perfectividad e impersonalidad. Madrid: Ediciones de la Universidad Autónoma de Madrid

DE ROBERTO, E. (20I2). Le costruzioni assolute nella storia dellitaliano. Napoli: Loffredo.

ERNOUT, A. y THOMAS, F. ( 1972). Syntaxe latine. Paris; Klincksieck.

FERNÁNDEZ LEBORANS, M. (1995). Sobre construcciones absolutas. Revista Española de Lingüística, 25/2, 365-395.

GAYNO, M. (20I5). Le participe en latin aux Vle et VIle S. ap. J-C. Syntaxe et sémantique. Paris: L'harmattan.

GÓMEZ TORREGO, L. (2000). Gramática didáctica del español. Madrid: SM.

GUTIÉRREZ ORDÓÑEZ, S. (1997). La oración y sus funciones. Madrid: Arco Libros.

HERNANZ, M. (199I). Spanish Absolute Constructions and Aspect. Catalan Working Papers in Linguistics, I, 75-I28.

HERNANZ, M. y SUÑER, A. (1999). La predicación: la predicación no copulativa. Las construcciones absolutas. En BOSQUE, I. y DEMONTE, V. (dirs.). Gramática descriptiva de la lengua española. Madrid: RAE-Espasa Calpe, 2525-2560.

HOFF, F. (1989). Les ablatifs absolus irréguliers : un nouvel examen du problème. En CALBOLI, G. (éd.). Subordination and Other Topics in Latin. Proceedings of the Third Colloquium on Latin Linguistics, Bologna, I-5 Abril 1985. Amsterdam: Studies in Language Companion Series 17, 40 I-423. 
LAPESA, R. (1975). Sintaxis histórica del adjetivo calificativo no atributivo. Homenaje al Instituto de Filología y Literaturas Hispanas "Dr. Amado Alonso" en su cincuentenario (1923-1973). Buenos aires, I71-199.

LÓPEZ, L. (1994). The Internal Structure of Absolute Small Clauses. Catalan Working Papers in Linguistics, 4, 45-92.

LORIAN, A. (1973). Tendances stylistiques dans la prose narrative française au XVle siècle. Paris: Klincksieck.

MARÍN, R. (2000). El componente aspectual de la predicación (tesis doctoral). Barcelona: Universidad Autónoma de Barcelona.

MARTÍNEZ, J. A. ( 1994). Cuestiones marginadas de gramática española. Madrid: Itsmo.

MEILÁN GARCÍA, A. J. (I99I). La oración simple en la prosa castellana del siglo XV. Oviedo: Departamento de Filología Española.

PÉREZ JIMÉNEZ, I. (2006). La gramática de las cláusulas absolutas de predicación en español (tesis doctoral). Madrid: Universidad Complutense de Madrid.

RAE (2009). Nueva gramática de la lengua española. Madrid: RAE-Espasa Calpe.

RAMAT, P. (1994). On Latin Absolute Constructions. En HERMAN, J. (éd.). Linguistic Studies on Latin, 6th International Colloquium on Latin Linguistics, Budapest, 23 27 mars 1991. Amsterdam; Studies in Language Companion Series 28, 259 268.

RUBIO, L. (1966). Introducción a la sintaxis estructural del latín, I, Barcelona: Ariel.

SERBAT, G. (1979). L'ablatif absolu. Revue des études latines, 57, 340-354.

SUÑER, A. (20/3). La diátesis de los participios en construcción absoluta: microvariación en la lengua escrita de los semicultos. Lingüística, 29/2, 5191.

TARRIÑO RUIZ, E. (2000). Construcciones participiales absolutas en Gregorio de Tours. Salamanca: Ediciones de la Universidad de Salamanca.

TOURATIER, C. (1994). Syntaxe latine. Louvain-la-Neuve: Peeters.

VANGAEVER, J. (20/8). Le gerundium et le participe présent en latin classique : perspectives typologiques. De Lingua Latina, I5, I-42. 
